\title{
Biogas Dome Construction Using Pneumatics
}

\author{
David Williamson', "John Orr² and David Fulford ${ }^{3}$
}

Published online: 15 January 2018

To cite this article: David Williamson, John Orr and David Fulford. (2017). Biogas dome construction using pneumatics. Journal of Construction in Developing Countries, 22(2): 35-53. https://doi.org/10.21315/jcdc2017.22.2.3

To link to this article: https://doi.org/10.21315/jcdc2017.22.2.3

\begin{abstract}
Fixed spherical dome biogas reactors are popular in Nepal for the production of biogas from waste materials. Current practice uses heaped soil as temporary formwork for an unreinforced concrete dome. This paper explores the structural requirements of biogas domes and presents a potential alternative construction process using air-supported flexible formwork that would be suitable for use in Nepal. A prototype dome was created to assess the feasibility of the formwork system. Load testing of the dome was undertaken to confirm structural performance. The results show that an air supported formwork system would be feasible for use in biogas domes with the formwork fabricated easily on site with only basic materials and fixings.
\end{abstract}

Keywords: Biogas, Fabric formwork, Shell design

\section{INTRODUCTION}

Biogas is a renewable energy technology, whereby combustible gas is produced from biological matter in a manmade container through the process of anaerobic respiration (Fulford, 2015). The technology is used around the world, most prominently in small households and farms with cattle in rural areas of developing countries, although references to biogas technology can be found as early as 10th Century BC (Fulford, 2015).

With $88 \%$ of the population owning livestock (Food and Agriculture Organization [FAO], 2011), Nepal has huge scope for increasing biogas production. It is estimated that the average Nepalese family could save up to 1.8 tonnes of firewood per year if they were able to build and install biogas reactor in their home (Fulford, 2015). The by-product of the anaerobic reaction can also be used to fertilise crops.

Concrete shells form a key component of biogas reactor design, yet they can be time consuming and expensive to build using conventional formwork systems. This paper explores the potential for air supported formwork to enable rapid and economical construction of large concrete domes in biogas reactors using easily transported formwork materials in remote locations.

\footnotetext{
'Department of Architecture and Civil Engineering, University of Bath, Bath, UK

${ }^{2}$ Department of Engineering, University of Cambridge, Cambridge, UK

${ }^{3}$ Kingdom Bioenergy Ltd, UK

"Corresponding email: jjo33@cam.ac.uk
} 


\section{Biogas Domes}

The two most popular biogas designs in Nepal are the floating steel drum and concrete fixed dome reactors (Figure 1). The floating steel drum is both prone to rusting and substantially more expensive than the concrete fixed dome design, which as a result is now more popular (Fulford, 2015).
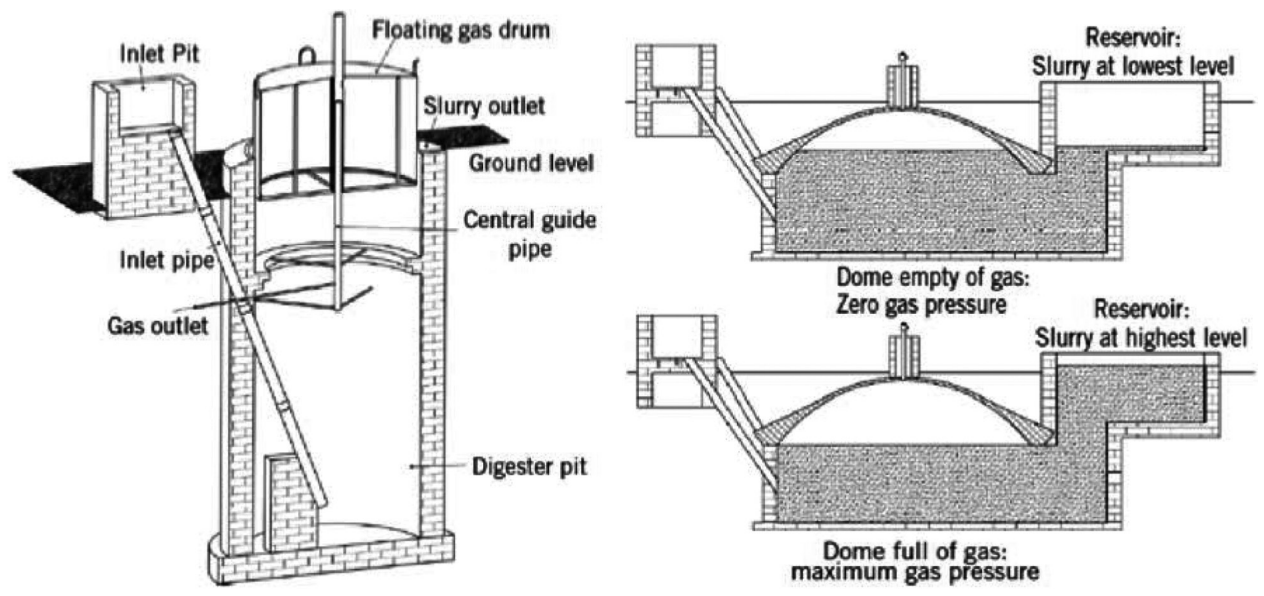

Figure 1. A Steel Drum Reactor (Left) and A Fixed Dome Reactor (Right) (Fulford, 2015)

The most complex element of the fixed dome reactor is the unreinforced concrete dome that covers the reactor. Current popular construction practice reuses excavated soil as temporary formwork for the concrete dome. After the reactor pit has been excavated and its walls completed, the soil is returned to the pit and formed into the shape of the dome, before a layer of concrete is cast over. Once the concrete has set, the soil is excavated through a reservoir on the side. This is a time consuming and labour-intensive process.

Transport is a key issue for construction of biogas domes, particularly in the mountainous regions of Nepal, where vehicular access is difficult. Heavy formwork systems such as steel or timber moulds would not be appropriate for transportation on foot by couriers. The limited access means that in the most rural areas, construction must rely primarily on labour rather than machinery.

Except for cement, which must be imported, the constituent materials of concrete can be sourced locally. Sand is typically dredged from rivers and aggregate sourced from landslides or by crushing rocks. This introduces the potential for great variability in concrete quality and manufacture depending on the site. Reinforcement in the form of bars or meshes would again be difficult to transport, but the use of short cut fibres to improve the tensile strength of the concrete dome would be feasible.

Under the right conditions, a mixture of methane (50\%-65\%), carbon dioxide $(30 \%-40 \%)$, and hydrogen sulphide $(\leq 1 \%)$ along with trace amounts of carbon monoxide, nitrogen, and hydrogen can be produced from the effluent (Fulford, 2015). Steel reinforcement in concrete structures is primarily protected from corrosion by the alkalinity of concrete. Carbonation of the concrete mix reduces 
the alkalinity through the conversion of calcium hydroxide in the cement paste to calcium carbonate and water. The reactor gases therefore means that the use of an unreinforced concrete dome is advantageous.

The dome construction must therefore:

1. Be durable, providing a long service life in an environment of high $\mathrm{CO}_{2}$ and other gases;

2. Use lightweight formwork that can be transportable across tough terrain;

3. Have a cheap, rapid, and reusable formwork to be competitive with current methods of construction and to allow multiple families to share the cost of a single formwork system.

\section{Construction Methods}

Current construction methods for fixed concrete dome reactors are both time consuming and labour intensive. Whilst the use of soil mould provides the ability to cast quite accurate geometries, as the desired dome size increases the feasibility of being able to excavate beneath the cast dome diminishes.

An alternative is proposed in which flexible inflated membranes are utilised to cast the unreinforced concrete shell using lightweight and easily transported materials. This proposal sits within a class of flexible formwork systems that have been applied to beams, columns, walls, panels, shells, and other structural elements (Araya and West, 2012; Tang and Pedreschi, 2015; Veenendaal, West and Block, 2011 ; West, 2007, 2013; West and Araya, 2009).

\section{Pneumatic Formwork}

One of the first applications of pneumatic formwork was a method of producing concrete pipes patented by Nose (1926) in 1926. Since then a common application of inflated membrane formwork has been the construction of dome-like structures for housing and agriculture (Neff, 1941a; Heifetz, 1972; Bini, 1967; South, 1990; Monolithic, 2014; YSM Ltd, 2014; PIRS SAS, 2014). Isler famously experimented with pneumatic formworks, inflating and spraying them with different materials like concrete, gypsum, clay, and water (Isler, 1979). As described by Sobek $(1986,1987)$ large pneumatic formworks can be significantly deformed during the production process. Schlaich and Sobek (1986) addressed this issue by using precast concrete segments to take up the deformations during assembly, with any gaps between these filled later with in-situ concrete. To minimise the effect wet concrete has on shape of the formwork, it is suggested that the concrete is applied in layers or sections.

In the 1960s pneumatic formwork was utilised for shell-houses (Bini, 1967, 1974). Special reinforcement is laid flat on the ground over a membrane before concrete is cast over. The membrane is then inflated to deform the concrete before setting into the doubly curved geometry. Over 1000 shells had been constructed with this method by 1986 (Roessler and Bini, 1986). A comprehensive overview of these methods is provided by Kromoser and Huber (2016). Further discussion, including some context of the history of shell construction methods, is provided by Tang (2015).

A new construction method using pneumatic formwork has been invented by Kromoser and Kollegger (2014), in which free-formed concrete shells originating 
from an initially flat plate can be built. During the transformation process, the hardened concrete plate consisting of petal shaped elements is bent with the aid of pneumatic formwork until the required curvature is reached (Figure 2b).

The use of a pneumatic mould could reduce build time for the biogas dome. The only requirements are the flexible formwork, an air pump, and a pressure regulator. Once fabricated, the inflation of the formwork is simple and intuitive - a plug and play construction method.
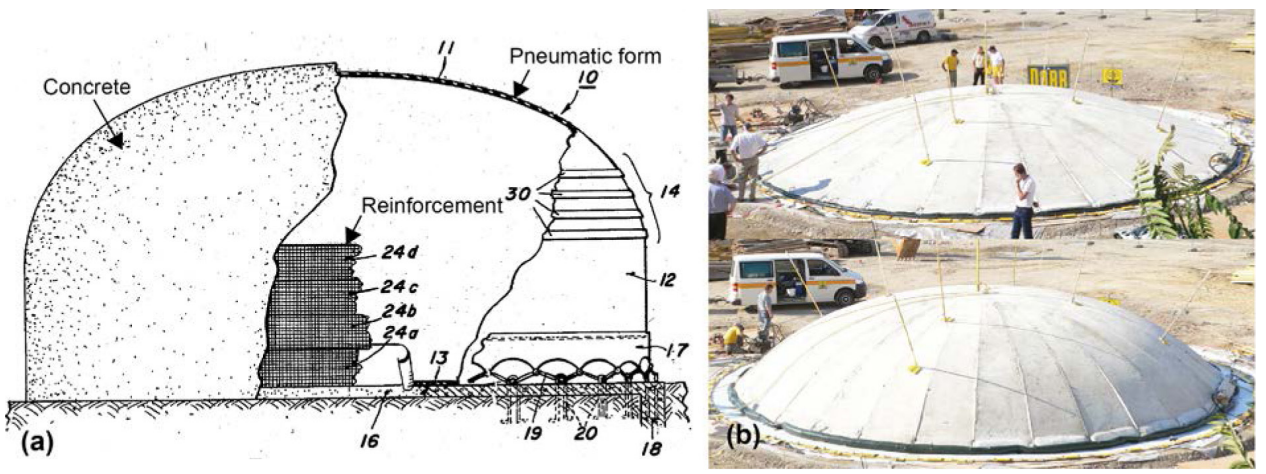

Figure 2. Pneumatic Formwork Examples: (a) Neff's Inflatable Method

(Neff, 1941b) and (b) Deforming a Segmented Concrete Plate (Kollegger, Kromoser and Dallinger, 2012)

\section{Shell Design}

Given the difficulty of transporting reinforcing materials, and the gas environment in the dome being unsuitable for steel reinforcement as noted above, a compression only shell is advantageous. A design method to achieve this goal is described below.

\section{Strength}

Self-weight forces in the meridional $\left(N_{\varphi}\right)$ and hoop $\left(N_{\theta}\right)$ directions of a shell cap with pinned boundary conditions can be determined using Eq. (1) and Eq. (2), while compression of the shell by applied external loading is determined by Eq. (3) (Timoshenko and Woinowsky-Krieger, 1959):

$$
\begin{aligned}
& N_{\varphi}=-\frac{p R}{1+\cos \varphi} \\
& N_{\theta}=p R\left(\frac{1}{1+\cos \varphi}-\cos \varphi\right) \\
& N_{\varphi}=N_{\theta}=-\frac{q R}{2}
\end{aligned}
$$

where $q$ is a uniform normal pressure $\left(\mathrm{kN} / \mathrm{m}^{2}\right), R$ is the radius of the shell, $p$ is the selfweight $\left(\mathrm{kN} / \mathrm{m}^{2}\right)$, and $\varphi$ is the angle axis of rotation from the shell (Figure 3 ). 


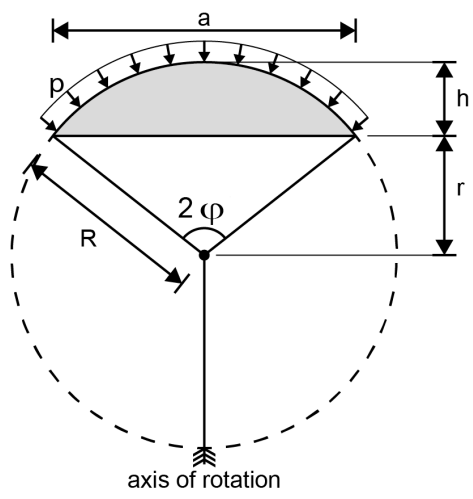

Figure 3. Shell Geometry

It follows from Eq. (2) that a shell segment cut from a hemisphere can be kept in compression in the hoop direction under self weight by limiting $\varphi$ to $51^{\circ} 50^{\prime}$ (Figure 3). The relationship between the height, $h$, span, $a$, and the angle $\varphi$ is given by Eq. (4).

$$
h=\frac{a}{2} \tan \left(\frac{\varphi}{2}\right)
$$

\section{Stability}

The buckling of perfect spherical caps calculated using linear elastic theory gives the critical buckling load in Eq. (5) (Zoelly, 1915):

$$
P_{c}=\frac{2 E}{\sqrt{3\left(1-V^{2}\right)}} \frac{t^{2}}{R^{2}}
$$

where $E$ is the Young's modulus, $n$ is Poisson's ratio, $t$ is the shell thickness, and $R$ is the shell radius of curvature.

Much subsequent research focused on producing realistic predictions of buckling loads for shells, recognising the importance of imperfections (Seaman, 1962; Krenzke and Kiernan, 1965; Von Karman and Tsien, 1939). In addition to geometrical imperfections, material properties and changes over time add another dimension to the buckling analysis of concrete caps (Hamed, Bradford and Gilbert, 2010; Dulácska, 1985). The reduction factor on the classical elastic buckling load in real shells is significant, with reported reductions of up to $96 \%$ in capacity (Kenaway, 2014). However, other authors report reductions in the region of $30 \%-35 \%$ (Von Karman and Tsien, 1939; Volmir, 1963). Given that construction accuracy is a key consideration in preventing buckling due to imperfections and that construction on site for biogas domes would not usually be very closely controlled, a conservative reduction factor on the elastic buckling capacity of $90 \%$ is taken as an initial design check, Eq. (6):

$$
P_{C}=0.1\left(\frac{2 E}{\sqrt{3\left(1-V^{2}\right)}} \frac{t^{2}}{R^{2}}\right)
$$




\section{Loading}

The reactor cover must be capable of withstanding the outward pressure of the gas within the reactor as well as any downward pressure of soil fill above, if used. Since the reactors are typically buried and covered, the second effect is dominant in most cases. Geometrical imperfections are a further key design consideration due to their propensity to induce buckling of the shell. In this work a conservative shell thickness, and buckling capacity was taken in design to mitigate against such effects.

The shell will be designed to carry imposed soil load as shown in Figure 4, where the various loading conditions are given by Eq. (7) - Eq. (10).

$$
\begin{aligned}
& p=\pi\left((a / 2)^{2}+h^{2}\right)(t)\left(\rho_{\text {concrete }}\right) \\
& q_{1}=\left(\frac{1}{3} \pi R^{3}\left(1-3 \sin ^{2} \alpha+2 \sin ^{3} \alpha\right)\right) \rho_{\text {soil }} \\
& q_{2}=\pi(a / 2)^{2}\left(q_{k}\right) \\
& q_{3}=\rho_{\text {eff }} g h_{2}
\end{aligned}
$$

where $a$ is the span, $h$ is the height, $t$ is the thickness, $\rho_{\text {concrete }}$ is the density of concrete $\left(24 \mathrm{kN} / \mathrm{m}^{3}\right), \mathrm{R}$ is the shell radius, $\alpha$ is shown in Figure $4, \rho_{\text {soil }}$ is the density of the soil, $q_{k}$ is the live load $\left(\mathrm{kN} / \mathrm{m}^{2}\right), \rho_{\text {eff }}$ is the density of the effluent, $g$ is gravity, and $h_{2}$ is the difference in height between the bottom of the dome and the top of the reservoir outlet (see Figure 1), treating the reactor like a manometer.

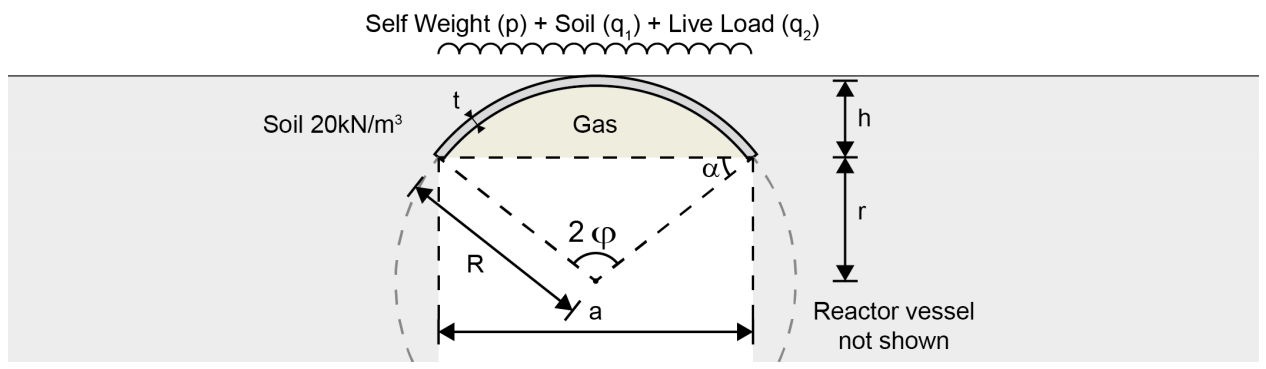

Figure 4. Shell Design Loading

\section{Feasible Dome Sizes}

Using the above equations, it is possible to plot simple relationships between dome geometry and loading to determine limiting dome sizes. In the following, the parameters given in Table 1 are used. 
Table 1. Shell Design Parameters

\begin{tabular}{cccccc}
\hline Parameter & Value & Parameter & Value & Parameter & Value \\
\hline$t$ & $70 \mathrm{~mm}$ & $\rho_{\text {concrete }}$ & $24 \mathrm{kN} / \mathrm{m}^{3}$ & $\rho_{\text {soil }}$ & $20 \mathrm{kN} / \mathrm{m}^{3}$ \\
$q_{\mathrm{k}}$ & $2 \mathrm{kN} / \mathrm{m}^{2}$ & $\rho_{\text {eff }}$ & $10 \mathrm{kN} / \mathrm{m}^{3}$ & $\varphi$ & $51^{\circ} 50^{\prime}$ \\
$\mathrm{E}$ & $30 \mathrm{GPa}$ & $v$ & 0.2 & & \\
\hline
\end{tabular}

The variation in meridional and hoop forces from self-weight, gas pressure, soil, and live loading with varying dome span is plotted in Figure 5. Summing these allows an estimation of the meridional and hoop forces in the dome to be made. This is shown in Figure 6. At a dome span of $13.8 \mathrm{~m}$, the forces in the hoop direction become tensile. This situation arises as self-weight hoop forces are approximately zero, and at this span the internal pressure caused by the effluent becomes larger than the external pressure from soil and live loading.
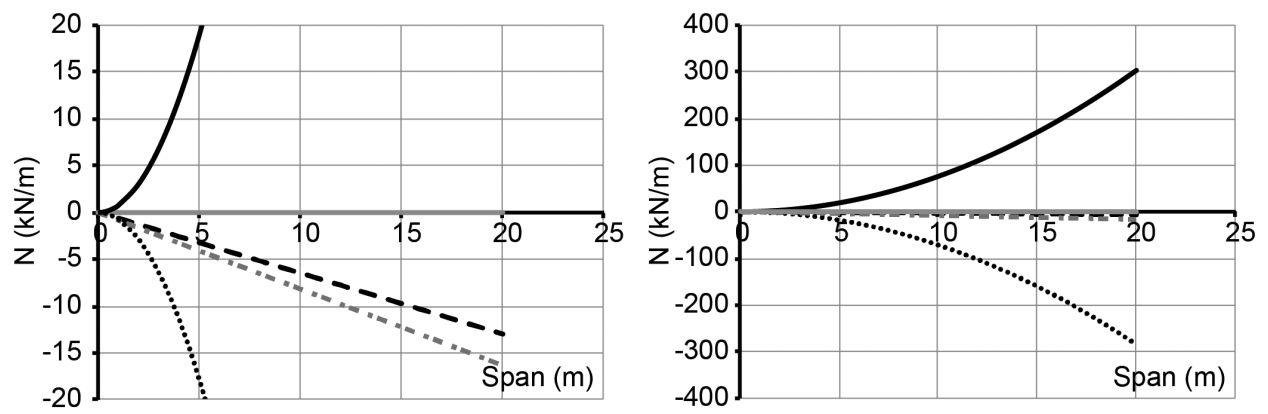

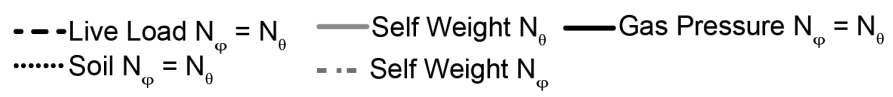

Figure 5. Variation with Dome Span for $\mathrm{N}_{\ominus}$ and $\mathrm{N}_{\varphi}$

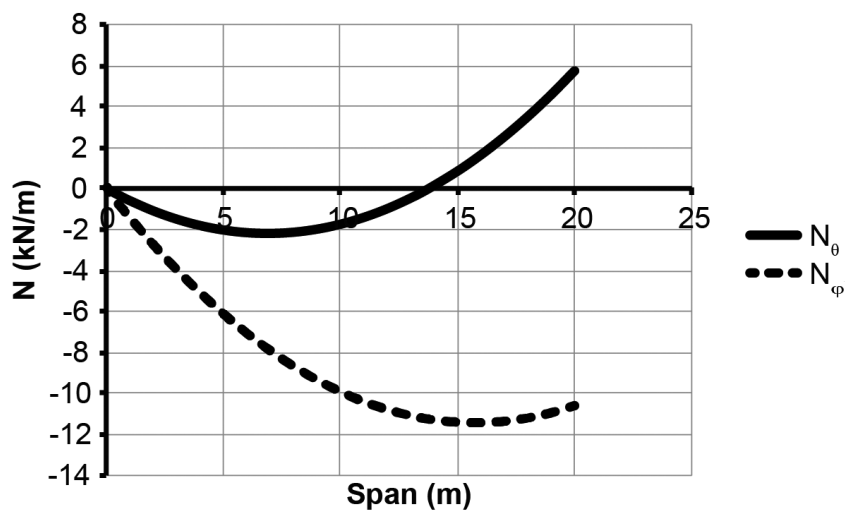

Figure 6. Sum of Meridonal and Hoop Forces in $70 \mathrm{~mm}$ Thick Shell 
Casting such a $13.8 \mathrm{~m}$ diameter dome would be difficult without complex additional scaffolding. A shell diameter of $5 \mathrm{~m}$ would allow casting with simple tools with a required tool reach of $\sim 2.5 \mathrm{~m}$, which would be feasible for construction in Nepal and is a size comparable to current construction practice (Fulford, 2015). At this size, simple falsework and hand tools would be sufficient to enable the casting process. Thickness gauges placed on the surface of the pneumatic mould provide a guide for the constructor to ensure a suitable and consistent thickness is achieved.

The buckling capacity of a $70 \mathrm{~mm}$ thick shell is shown in Figure 7 over the same span range, using Eq. (6). It is clear that in realistically sized concrete shells, the buckling capacity is sufficiently high to not be a concern. In very long span or very thin shells (which would be difficult to build) buckling may be an issue.

Following the process above it is possible to determine: (1) span-height ratios that keep the shell in compression under self-weight (Eq. [4]); (2) approximately the forces within the shell under the loading conditions for which it is being designed; and (3) to propose a suitable shell thickness based on buckling and strength considerations.

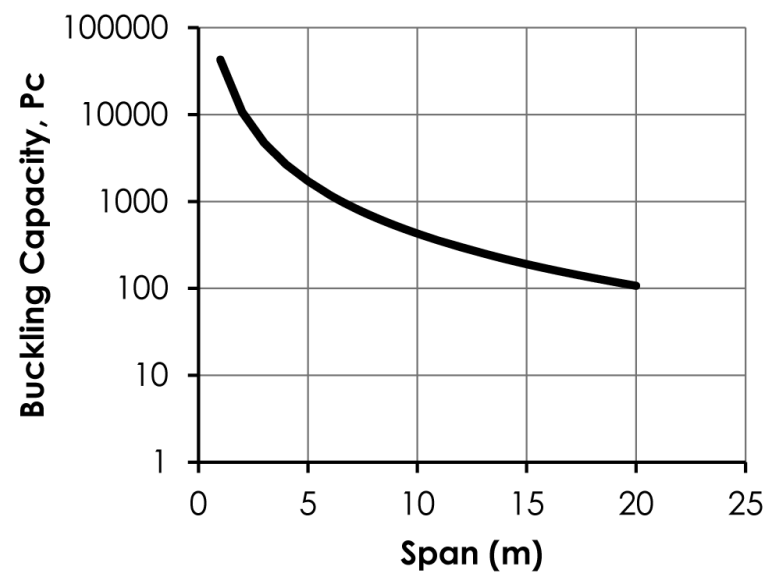

Figure 7. Buckling Capacity of $70 \mathrm{~mm}$ Thick Shell

\section{Dome Prototype}

A $2 \mathrm{~m}$ diameter and $70 \mathrm{~mm}$ thick prototype dome was cast and tested to determine the feasibility of the construction process using methods and materials appropriate for application in Nepal. The dome formwork was monitored during construction, and the shell subsequently proof load tested to demonstrate the feasibility of the construction method. The total applied load, calculated using Eq. (8) and Eq. (9) is $6.5 \mathrm{kN} / \mathrm{m}^{2}$ for a $2 \mathrm{~m}$ diameter dome. 


\section{MATERIALS}

\section{Concrete}

Following work by Devkota (2001) a concrete mix representative of that used in Nepal was designed, as shown in Table 2. Most of the main constituents of the concrete can be found within Nepal (sand is typically sifted from the nearest local stream near the site, aggregate can be made from crushing rocks or by from landslides, but cement must be imported). The prototype mix was sufficiently stiff to be applied to the sloping dome formwork, slump was measured at $45 \mathrm{~mm}$ in a test carried out in accordance with BS EN 12350 (British Standards Institute [BSI], 2009).

Table 2. Mix Design

\begin{tabular}{lllll}
\hline Constituent & $\begin{array}{c}\text { Recommendation } \\
\text { (Devkota, 2001) }\end{array}$ & \multicolumn{1}{c}{$\mathbf{k g} / \mathbf{m}^{3}$} & \multicolumn{1}{c}{ Prototype Mix } & $\mathbf{k g} / \mathbf{m}^{\mathbf{3}}$ \\
\hline Cement & Portland Cement & 320 & CEM I & 320 \\
Sand & River bed sand & 960 & Marlborough Grit $-5 \mathrm{~mm}$ & 960 \\
Aggregate & $20-25 \mathrm{~mm}$ "pebbles" & 960 & Mendip Limestone $-10 \mathrm{~mm}$ & 960 \\
Water & "Workable" & "Workable" & 0.5 w/C ratio & 160 \\
\hline
\end{tabular}

\section{Formwork Material}

A reinforced PVC airbag material $(0.24 \mathrm{~mm}$ thickness, 1100 Dtex) was used as the formwork in this study. The material was obtained from a commercial supplier of airbag fabrics. No patterning machinery was required: the fabric was cut with scissors and seams joined with a widely available waterproof polyurethane polymer solvent paste to ensure an airtight seal (Bostik, 2016), demonstrating the feasibility of the method for Nepal. The seams all had a $60 \mathrm{~mm}$ bonded area and glve was applied uniformly to the bonded surface. To assemble the fabric wedges, simple timber guides were cut to the correct geometry and clamped around the fabric to maintain an even pressure on the bonded areas during setting of the glve.

The hemispherical shape of the dome was chosen to simplify the design process and to ensure that the formwork could easily be patterned. The formwork was to be constructed in appropriately shaped panels with a circular capping piece at the apex of the dome (Figure 8).

Formwork patterning was undertaken using a simple excel script that linked meridian length and hoop length for a given wedge angle (see also Harris and Stocker, 1998) to generate the geometry of the flat formwork pieces required to create the dome. The geometry of hemispherical domes is well documented elsewhere, e.g. Arfken (1985). The number of "wedges" was a balance between geometrical accuracy (fewer wedges) and construction complexity (more wedges). A wedge angle of $22.5^{\circ}$ was chosen as a suitable balance between these two extremes (Figure 8). 


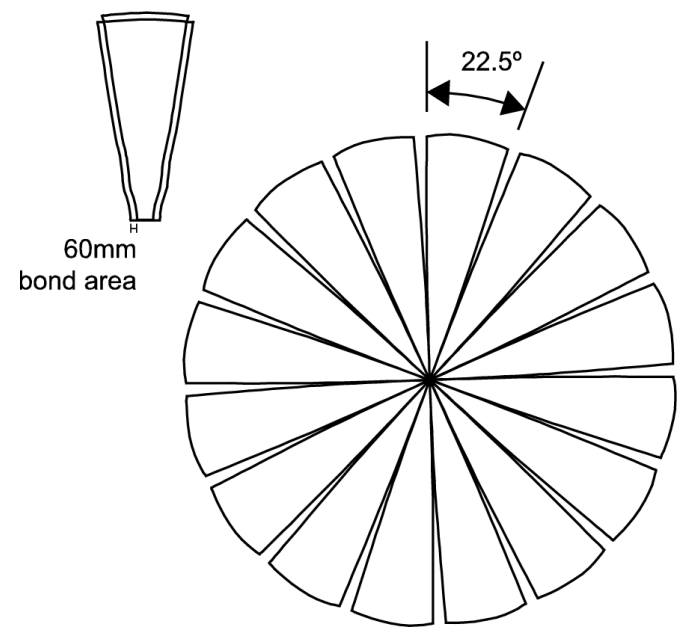

Figure 8. Formwork Patterning Design

\section{Construction}

\section{Membrane formwork}

Once cut to the appropriate shapes, the membrane was joined with soft plastic glue. A $60 \mathrm{~mm}$ bond area between wedges was used to ensure an airtight seal and appropriately shaped clamps were applied during glve curing. An air inlet and pressure gauge were fitted to the formwork.

\section{Ring beam}

The prototype construction did not include the reactor pit, and so a simple ring beam was required to resist outward thrust of the shell during construction. An octagonal structure was designed to resist the calculated outward thrust. The ring beam was fixed to the laboratory floor during testing to provide a stiff edge connection to the shell representative of the in-situ condition.

\section{Casting}

The shell construction process is illustrated in Figure 9. The formwork was inflated to $87 \mathrm{kPa}$ prior to concrete casting (Figure 9d). The pressure was chosen during inflation based on the rigidity of the mould, assessed by gently pressing on the mould by hand. Concrete was then applied to the dome first around the ring beam edge (Figure 9e) and then evenly over the dome surface in thin layers until the desired $70 \mathrm{~mm}$ thickness was applied. The mould was able to deform during the casting process, making the even spreading of the concrete important to the final geometry. Applying concrete to the centre of the prototype dome required tools with a $1 \mathrm{~m}$ reach, which was achieved with conventional hand tools. The thickness of the shell was monitored using an evenly spaced grid of blunt-ended $3 \mathrm{~mm}$ diameter timber rods placed perpendicular to the mould surface. The rods allowed 
the thickness to be gauged during casting, and were subsequently removed once the required thickness was reached.
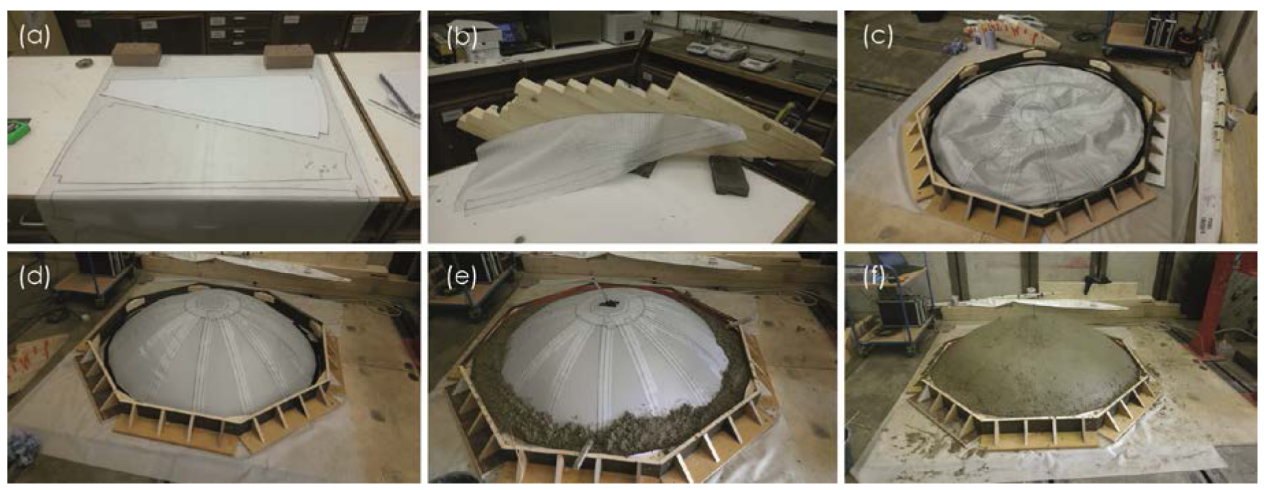

Figure 9. Dome Construction Sequence: (a) Cutting Pattern; (b) Gluing Sections;

(c) Assembly Within Ring Beam; (d)-(f) Inflation and Casting

The concrete was applied by hand, but could feasibly also have been sprayed onto the surface. In a larger shell, this may be a preferred method as walking on the inflated surface would not be advised. Pressure in the formwork was monitored throughout the casting and curing process, as shown in Figure 10. The dome was deflated after 24 hours.

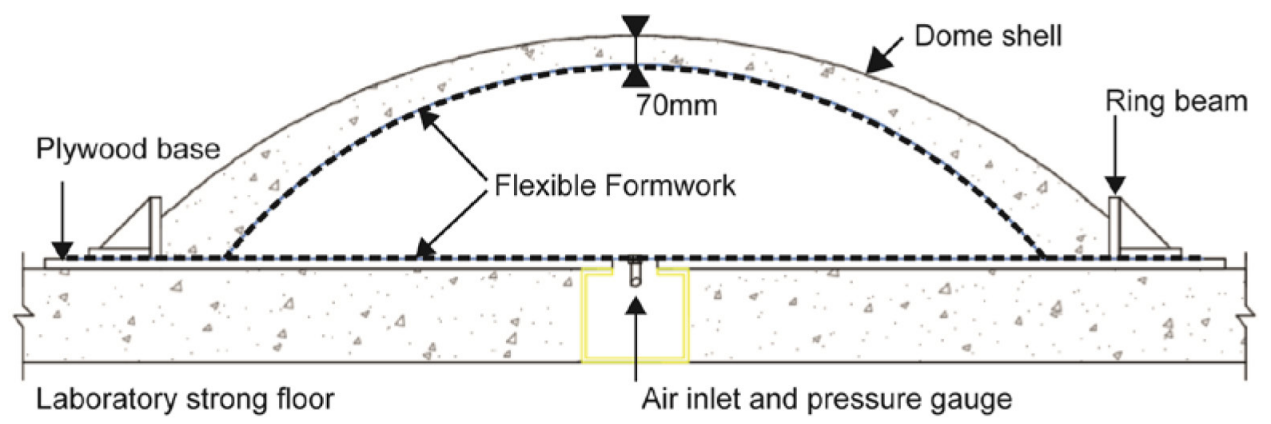

Figure 10. Laboratory Set Up

\section{Testing}

\section{Method}

The prototype dome was tested using sand bag loading 7 days after casting. Sand bags of $20 \mathrm{~kg}$ each were placed on the dome, starting at the ring beam and adding rows along the hoop direction. Once a single layer was present across the dome surface, the process was repeated in a uniform pattern up to a maximum load of $24.4 \mathrm{kN}\left(7.8 \mathrm{kN} / \mathrm{m}^{2}\right)$ excluding self-weight. The loading was applied as shown in Figure 11. 


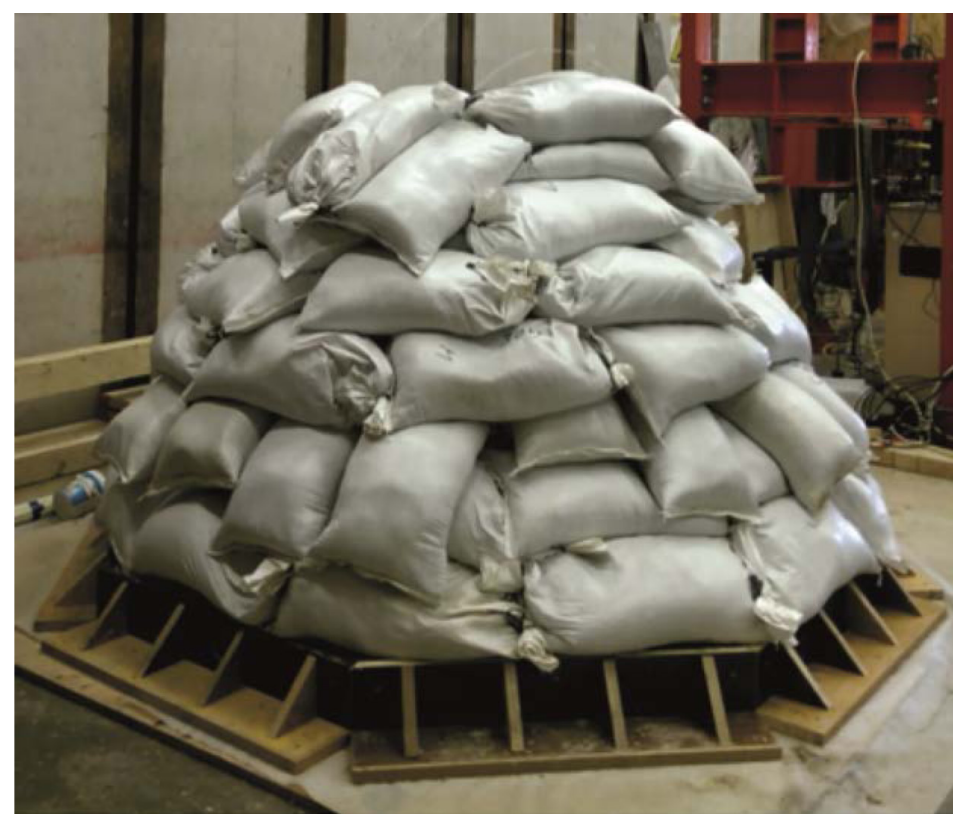

Figure 11. Loading of Dome Prototype

\section{RESULTS}

One hundred mm cube tests were used to determine the compressive strength of the concrete. Results taken at the test date and 21 days after casting are shown in Table 3.

Table 3. 7 Day and 21 Day Cube Test Averages

\begin{tabular}{lcc}
\hline & 7 day & 21 day \\
\hline Mean strength (MPa) & 34.6 & 41.3 \\
Standard deviation (MPa) & 3.87 & 2.57 \\
Number of cube samples & 8 & 4 \\
\hline
\end{tabular}

\section{Pressure Readings}

The pneumatic formwork pressure was monitored throughout inflation, casting, and curing. The pressure results are shown in Figure 12. Pressure was monitored for four days during curing. A pressure gauge and laboratory data logger at $10 \mathrm{~Hz}$ allowed the data collection shown in Figure 12. The airline was removed during load testing of the shell. 


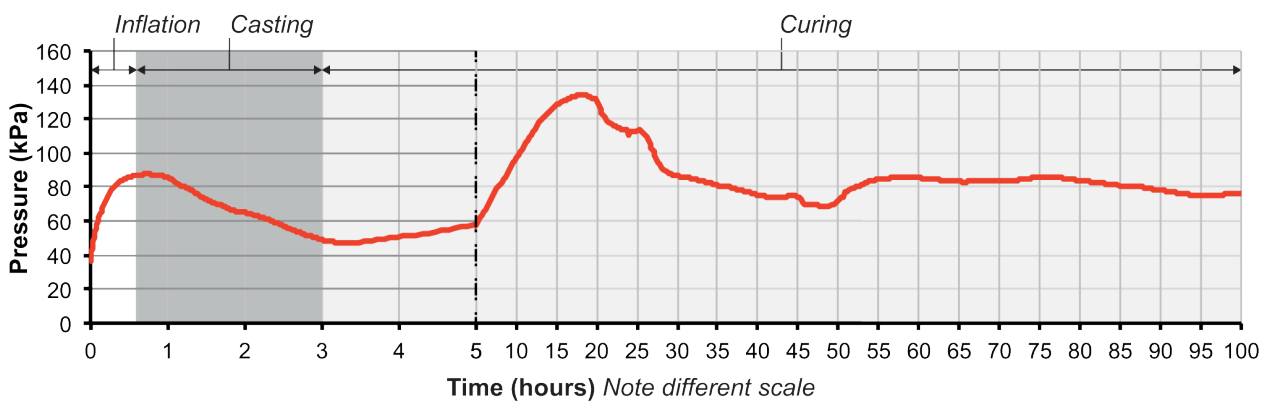

Figure 12. Pressure Readings for 100 Hours from Inflation

\section{Dome geometry}

To assess the construction accuracy of the dome, the cast surface was measured by taking four slices of the dome. A comparison between as-built and intended geometry is shown in Figure 13. The slice locations are shown in Figure 14.

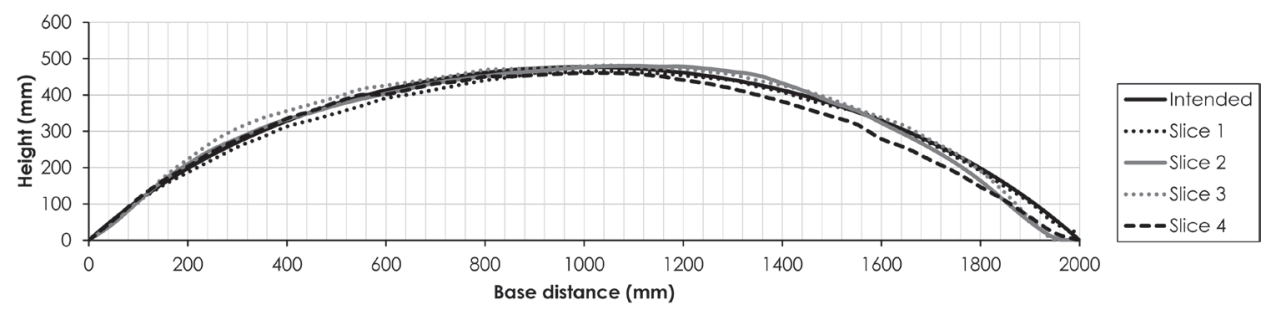

Figure 13. Inner Dome Slices Compared to Intended Height

\section{DISCUSSION OF EXPERIMENT AND RESULTS}

\section{Geometry}

The average error in geometry, defined by a percentage difference between intended and actual geometry, is given in Table 4 and Figure 14. The results, illustrated graphically in Figure 15, show that the majority of the error has arisen in the support zones. The average error in geometry along each slice, calculated by comparing the actual geometry to the designed geometry at $50 \mathrm{~mm}$ intervals along the diameter of the slice (see Figure 13), is small at only $3 \%$ difference. However, in localised regions around the support locations the error was found to be much higher, reaching $54 \%$ in one case. 


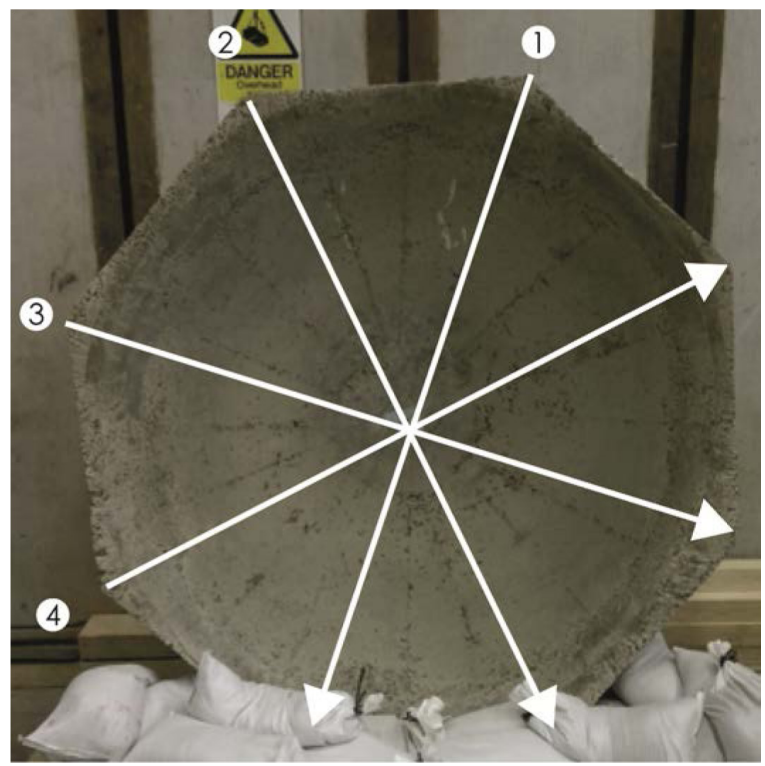

Figure 14. Slice Location and Direction

The dome was removed from its formwork for inspection (Figure 14) by releasing the timber ring beam and simply lifting the shell up. The pneumatic formwork does not remain stuck to the underside of the shell, making it feasible to be reused.

Table 4. Average Error Identified in the Dome Construction

\begin{tabular}{ccccc}
\hline Slice 1 & Slice 2 & Slice 3 & Slice 4 & Average \\
\hline$-4 \%$ & $-3 \%$ & $1 \%$ & $-6 \%$ & $-3 \%$ \\
\hline
\end{tabular}

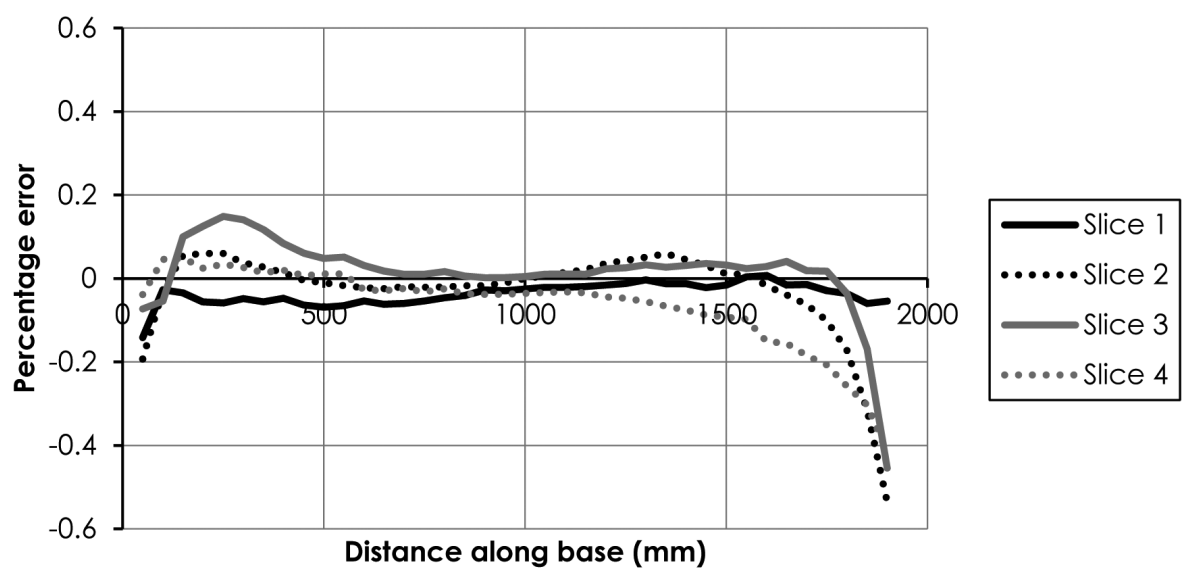

Figure 15. Construction Error Identified in Four Slices of The Prototype Dome 


\section{Strength and Stability}

The dome passed the loading test, reaching a total imposed load of $7.8 \mathrm{kN} / \mathrm{m}^{2}$ without failure. This is greater than the $6.5 \mathrm{kN} / \mathrm{m}^{2}$ design imposed load. The capacity of the dome is expected to be significantly greater than this, but experimental limitations meant that additional load could not be applied to the shell.

Geometrical imperfections in shell structures are a crucial consideration. Analysis of the cast shell showed on average $-3 \%$ deviation in geometry between the as-designed and as-built shells. In some areas of the shell more significant imperfections were seen. The modelling took a very conservative reduction factor in calculating buckling capacity of the shell and this appears to have been a successful, but potentially conservative approach that simplifies the calculation process considerably.

Pressure readings taken during casting showed the formwork peaked at around $87 \mathrm{kPa}$ within 36 minutes pre-casting. When casting began, the pressure began to noticeably decrease as the concrete was applied to the dome. The most likely cause for this was the outflow of air pressure began to increase as the concrete was applied, resulting in it exceeding the inflow of air, causing the pressure to drop. This began to increase again after casting had finished when the concrete started to cure. Within a day the concrete had set, and the airline to the formwork was switched off.

The pressure drop raised an expected issue with the formwork, however the flow from the airline was relatively low. If a pump with a higher flow was used in the field, it would negate this issue. Despite this, formwork had generally responded well during the casting process. Once the formwork had been covered completely, judging the dome thickness became difficult. However, the formwork would bulge where there was less concrete, and bow where there was too much, giving a general indicator of the concrete distribution.

To assess the feasibility of reusing the formwork, the membrane was reinflated after demoulding. Some damage was noted and an air pressure of only $33 \mathrm{kPa}$ could be maintained. Holes in the formwork had formed primarily around the seams (which had been sealed with low cost glve). However, the fabric itself is very low cost and easily transported, so reusability is not a major concern. The seams are clearly of vital importance to ensure that leaks do not occur during the casting process. If a significant leak did occur, deflation of the membrane and removal of the wet concrete would be required. This can be avoided by ensuring that seams have a sufficient overlap (60 mm was used here), gluing is undertaken with care to avoid gaps, and the mould is pressure tested prior to concrete casting.

The inner dome analysis showed that the inner geometry of the dome was close to the intended geometry. All four slices showed consistency in the readings, with a maximum variation between readings being $70 \mathrm{~mm}$. The only marked difference was the readings dropped off towards the end, which showed that each slice was not equal in length. The average was very representative of the intended geometry. Not only does this show consistency throughout the formwork, but it also shows the formwork was accurate to its intended geometry. This shows that the number of wedges chosen was sufficient and that the fabrication process of the formwork is simple enough to be repeated. 


\section{CONCLUSIONS}

This paper has shown that unreinforced concrete reactor domes using a preinflated air formwork are feasible. The formwork was created and made using simple hand tools appropriate to all regions. The finished inner surface of the dome was, on average, within $3 \%$ of the intended geometry of the formwork, showing the formwork provides an accurate shape for unreinforced domes. Theoretical analysis shows that larger unreinforced domes are structurally feasible, and the calculations required are minimal. Gas pressure within the reactor is an issue for larger domes but can be managed by increasing the dome thickness or increasing the soil cover on the dome.

\section{RECOMMENDATIONS FOR FURTHER WORK}

Further tests on full-scale prototype structures with strain gauges on the concrete surface, and testing to full buckling capacity should be undertaken. The effect of imperfections and reduction factors for the shell buckling equation should be studied in additional tests. Nepal is situated in an earthquake region, and further studies should be undertaken to establish the performance of such domes under seismic loading, including strategies to provide sufficient ductility to the design, perhaps through the use of a steel fibre reinforced concrete mix.

The inflatable dome formwork was successfully used once, but re-inflation was not possible due to leaks. Further work is required to develop more robust joining methods to allow for reuse of the formwork. The inflatable mould can feasibly be fabricated in a variety of geometries. Further work on more complex shell shapes is required, including catenary shells where greater material efficiencies may be found. Hybrid systems that combined deployable timber gridshells with pneumatics may be a further viable avenue for construction, following proposals by Tang and Pedreschi (2015).

\section{ACKNOWLEDGEMENTS}

The authors gratefully acknowledge the technical support of the University of Bath Department of Architecture and Civil Engineering given during the experimental work described in this paper.

\section{REFERENCES}

Araya, R. and West, M. (2012). Flat sheet fabric moulds for double curvature precast concrete elements. Proceedings of the Second International Conference on Flexible Formwork. University of Bath, Bath, 27-29 June 2012.

Arfken, G. (1985). Spherical polar coordinates. Mathematical methods for physicists, 3rd Ed. Orlando, FL: Academic Press.

Bini, D. (1967). A new pneumatic technique for the construction of thin shells. Proceedings from the 1st IASS International Colloquium on Pneumatic Structures. University of Stuttgart, Germany, 11-12 May 1967. 
Bini, D. (1974). Concrete domes. Official Journal of the Masters Builders' Association of New South Wales, 3(7): 326-334.

Bostik. (2016). Soft plastics adhesive. Stafford, England: Bostik.

British Standards Institute (BSI). (2009). BS EN 12350: Testing fresh concrete. London: BSI.

Devkota, G.P. (2001). Biogas technology In Nepal: A sustainable source of energy for rural people. Kathmandu: B Devkota.

Dulácska, E. (1985). Buckling analysis of reinforced concrete shells. Proceedings of Inelastic Behaviour of Plates and Shells, IUTAM Symposium. Rio de Janeiro, Brazil, 5-9 August 1985.

Food and Agriculture Organization (FAO). (2011). World livestock 2011 - Livestock in food security. Rome: FAO.

Fulford, D.J. (2015). Small scale rural biogas programmes. Rugby, Warwickshire, UK: Practical Action Publishing. https://doi.org/10.3362/9781780448497

Hamed, E., Bradford, M.A. and Gilbert, R.I. (2010). Nonlinear long-term behaviour of spherical shallow thin-walled concrete shells of revolution. International Journal of Solids and Structures, 47(2): 204-215. https://doi.org/10.1016/j. ijsolstr.2009.09.027

Harris, J.W. and Stocker, H. (1998). Spherical segment (spherical cap). Handbook of mathematics and computational science. New York: Springer-Verlag.

Heifetz, H. (1972). Inflatable forms. U.S. Pat. 3,643,910.

Isler, H. (1979). New materials for shell and spatial structures. Proceedings of IASS world conference. Madrid.

Kenaway, M. (2014). A proposed segmented precast concrete spherical cap: Geometry, structural stability and construction. MSc. diss., The American University in Cairo.

Kollegger, J., Kromoser, B. and Dallinger, S. (2012). The building of ice and concrete shells by employing pneumatic formwork. Proceedings of Second International Conference on Flexible Formwork. Bath, University of Bath, 27-29 June 2012.

Krenzke, M.A. and Kiernan, T.J. (1965). The effect of initial imperfections on the collapse strength of deep spherical shells, David Taylor Model Basin Report 1757. Washington, USA: Department of the Navy. https://doi.org/10.21236/ AD0612100

Kromoser, B. and Huber, P. (2016). Pneumatic formwork systems in structural engineering. Advances in Materials Science and Engineering. https://doi. org/10.1155/2016/4724036

Kromoser, B. and Kollegger, J. (2014). Herstellung von Schalentragwerken aus Beton mit der "Pneumatic Wedge Method" - Ein neves Bauverfahren für den Bau von zweifach gekrümmten Betonflächen (Production of shell structures made of concrete with the "Pneumatic Wedge Method" - A new construction method for the construction of double-curved concrete surfaces). Betonund Stahlbetonbau, 109(8): 557-565. https://doi.org/10.1002/best.201400014

Monolithic. (2014). The monolithic dome. Available at: http://www.monolithic.org/ topics/domes [Accessed on 15 September 2016].

Neff, W. (1941a). Building construction. U.S. Pat. 2,270,229.

Neff, W. (1941b). Improved method of erecting shell-form concrete structures. USA patent application 2,892,239.

Nose, T. (1926). Process of constructing culverts of pipes of concrete. U.S. Pat. $1,600,353$. 
PIRS SAS. (2014). Dome construction. Available at: http://www.domepirs.com/en/ welcome [Accessed on 15 September 2016].

Roessler, S. and Bini, D. (1986). The Binishell system - Thin shell concrete domes. Concrete International, 8(1): 49-53.

Schlaich, J. and Sobek, W. (1986). Suitable shell shapes. Concrete International, January(1986): 41-45.

Seaman, L. (1962). The nature of buckling in thin spherical shells. PhD diss., Massachusetts Insitute of Technology.

Sobek, W. (1986). Concrete shells constructed on pneumatic formwork. Proceedings of IASS Symposium on Membrane Structures and Space Frames. Osaka, Japan, 15-19 September 1986.

Sobek, W. (1987). Auf pneumatisch gestützten Schalungen hergestellte Betonschalen (Pneumatically assisted formwork for concrete shells). Stuttgart: Verlag Ursula Sobek.

South, D. B. (1990). Economics and thin shell dome. Concrete International Magazine, 12(8): 24-29.

Tang, G. (2015). An overview of historical and contemporary concrete shells, their construction and factors in their general disappearance. International Journal of Space Structures, 30(1): 1-12. https://doi.org/10.1260/0266-351 1.30.1.1

Tang, G. and Pedreschi, R. (2015). Deployable gridshells as formwork for concrete shells. Proceeding of IASS ISOFF. Amsterdam, 16-17 August 2015.

Timoshenko, S. and Woinowsky-Krieger, S. (1959). Theory of plates and shells. New York: McGraw-Hill.

Veenendaal, D., West, M. and Block, P. (2011). History and overview of fabric formwork: Using fabrics for concrete casting. Structural Concrete, 12(3): 164177. https://doi.org/10.1002/suco.201100014

Volmir, A. (1963). Stability of elastic systems. Mosow: Fizmatgiz.

Von Karman, T. and Tsien, H.S. (1939). The buckling of spherical shells by external pressure. Journal of the Aeronautical Sciences, 7(2): 43-50. https://doi. org/10.2514/8.1019

West, M. (2007). CAST construction. Winnipeg, Manitoba, Canada: University of Manitoba.

West, M. (2013). Fabric-formed precast panels - Simple, economical, formwork for natural forms and structurally efficiency. Facade Tectonics Journal: Precast Concrete, 1 (1): 93-100.

West, M. and Araya, R. (2009). Fabric formwork for concrete structures and architecture. Proceedings of International Conference on Textile Composites and Inflatable Structures, Structural Membranes. Stuttgart, Germany, 5-7 October 2009.

YSM Ltd. (2014). DOMECRETE building system. Available at: http://ysmforbuilding. com/en/domecrete-domes-building-system [Accessed on 15 September 2016].

Zoelly, R. (1915). Uber ein Knickungsproblem an der Kugelschale (On the problem of buckling of the spherical shell). PhD diss., ETH Zurich. https://doi.org/10.3929/ ethz-a-000091951 


\title{
APPENDIX
}

\author{
$N_{\varphi} \quad$ Meridonal force $(\mathrm{kN} / \mathrm{m})$ \\ $N_{\theta} \quad$ Hoop force $(\mathrm{kN} / \mathrm{m})$ \\ $p \quad$ Self weight $\left(k N / m^{2}\right)$ \\ q Live load $\left(\mathrm{kN} / \mathrm{m}^{2}\right)$ \\ $R \quad$ Radius of curvature $(\mathrm{m})$ \\ a Shell span $(\mathrm{m})$ \\ $h \quad$ Shell rise $(\mathrm{m})$ \\ $P_{c} \quad$ Critical buckling pressure \\ $g \quad$ Acceleration due to gravity \\ $t \quad$ Shell thickness $(\mathrm{m})$ \\ E Young's Modulus \\ $v \quad$ Poisson's Ratio
}

